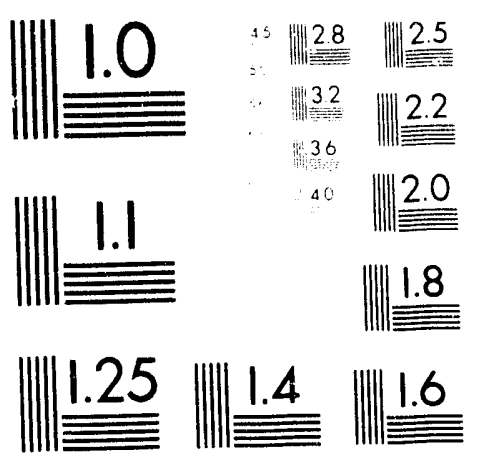



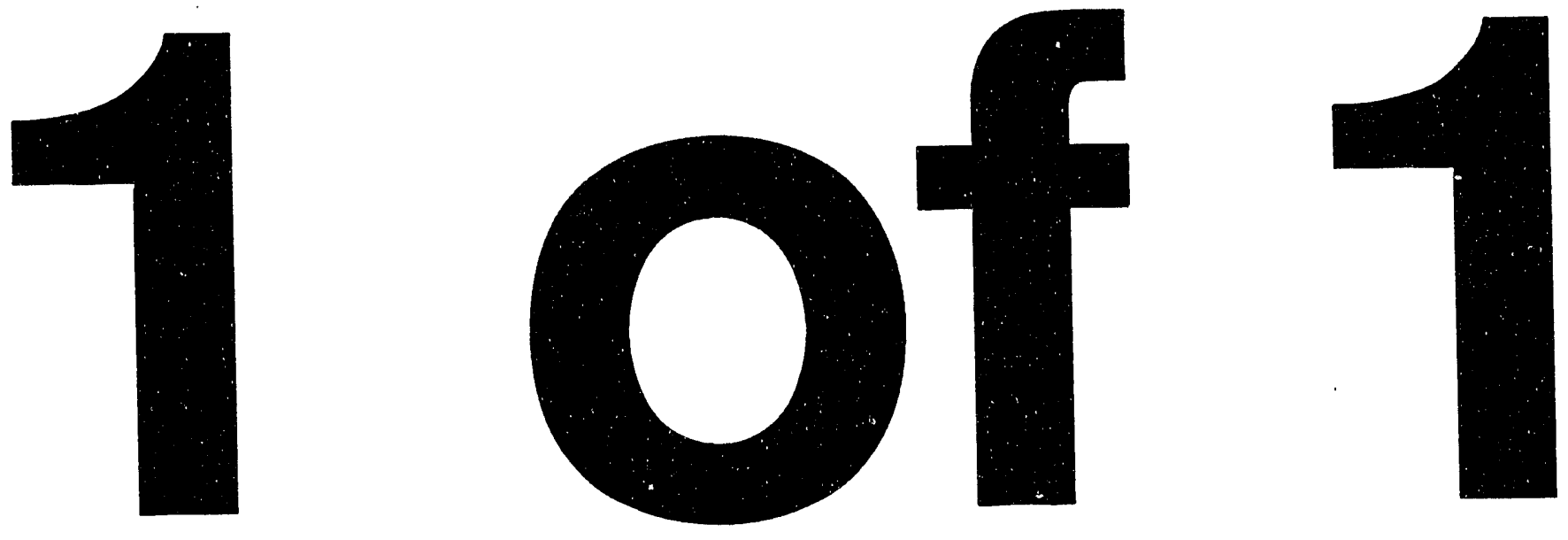
Defense Nuclear Agency Alexandria, VA 22310-3398

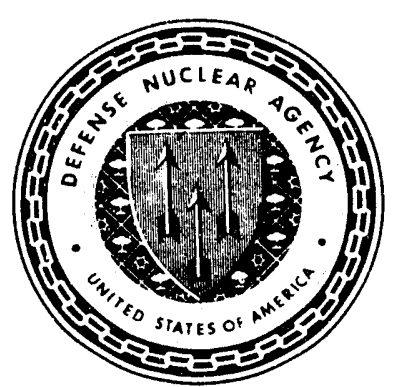

DNA-TR-93-62

\section{Survivability Validation Protocol Issues for a System-of-Systems}

\section{Gary Brock}

Kurt J. lanacone

Thomas A. Stringer

Kaman Sciences Corp.

P.O. Box 7463

Colorado Springs, CO 80933-7463

August 1993

Technical Report

CONTRACT NO. DNA 001-89-C-0080 
Destroy this report when it is no longer needed. Do not return to sender.

PLEASE NOTIFY THE DEFENSE NUCLEAR AGENCY, ATTN: CSTI, 6801 TELEGRAPH ROAD, ALEXANDRIA, VA 22310-3398, IF YOUR ADDRESS IS INCORRECT, IF YOU WISH IT DELETED FROM THE DISTRIBUTION LIST, OR IF THE ADDRESSEE IS NO LONGER EMPLOYED BY YOUR ORGANIZATION. 


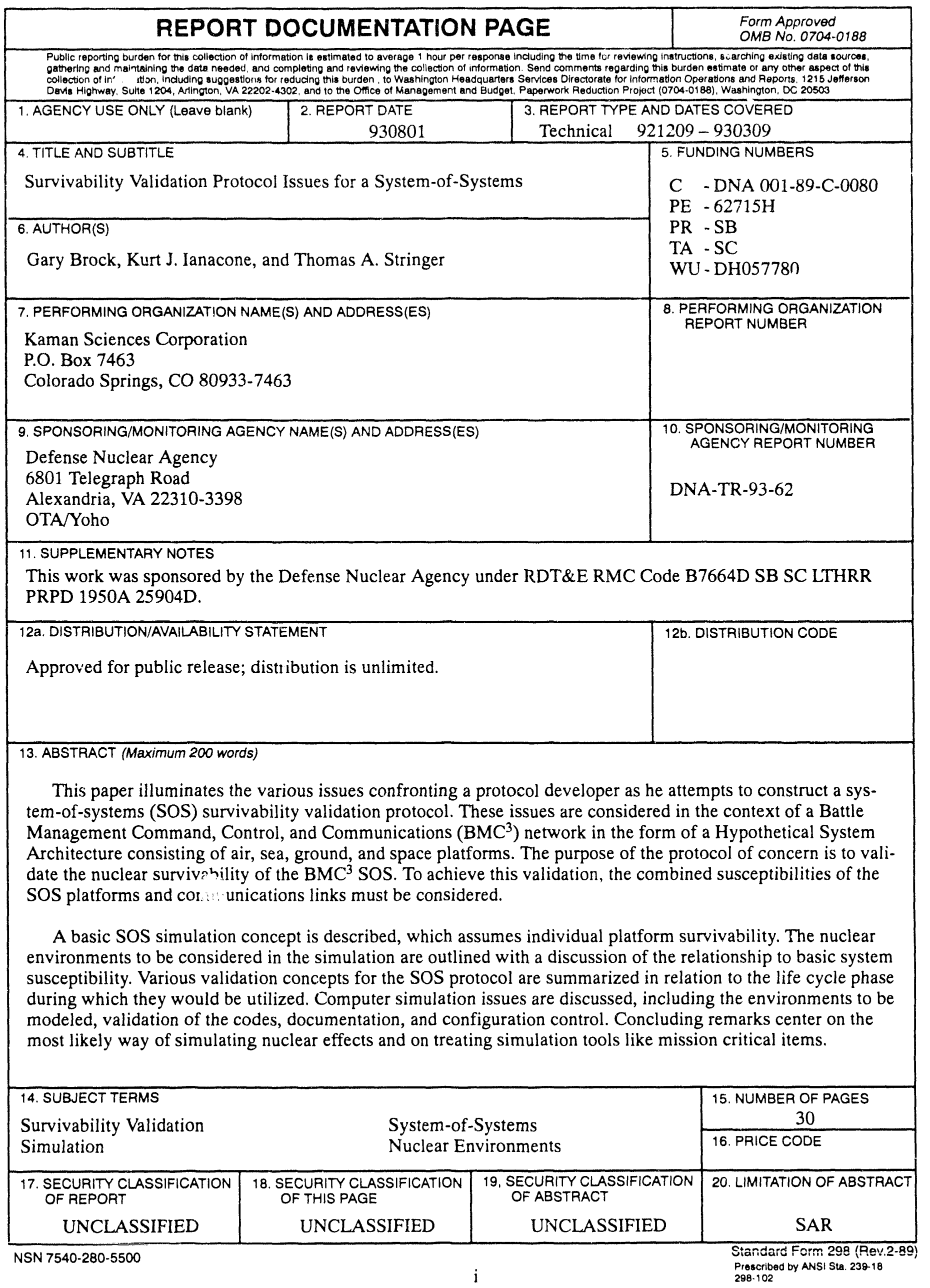


UNCLASSIFIED

SECURITY CZASSIFICATION OF THIS PAGE

CLASSIFIED BY

N/A since Unclassified.

DECLASSIFY ON:

N/A since Unclassified. 


\section{SUMMARY}

This paper illuminates the various issues confronting a protocol developer as he attempts to construct a system-of-systems (SOS) survivability validation protocol. These issues are considered in the context of a Battle Management Command, Control, and Communications $\left(\mathrm{BMC}^{3}\right)$ network in the form of a Hypothetical System Architecture consisting of air, sea, ground, and space platforms. The purpose of the protocol of concern is to validate the nuclear survivability of the $\mathrm{BMC}^{3}$ SOS. To achieve this validation, the combined susceptibilities of the SOS platforms and communications links must be considered.

A basic SOS simulation concept is described, which assumes individual platform survivability. The nuclear environments to be considered in the simulation are outlined with a discussion of the relationship to basic system susceptibility. Various validation concepts for the SOS protocol are summarized in relation to the life cycle phase during which they would be utilized. Computer simulation issues are discussed, including the environments to be modeled, validation of the codes, documentation, and configuration control. Concluding remarks center on the most likely way of simulating nuclear effects and on treating simulation tools like mission critical items. 


\section{TABLE OF CONTENTS}

Section

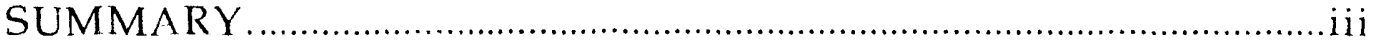

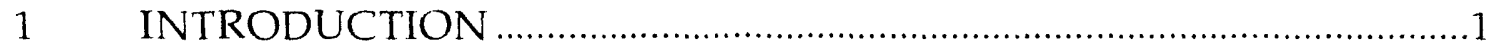

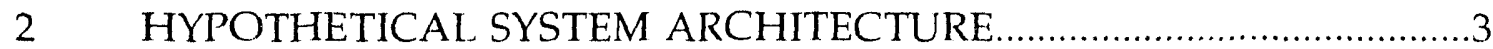

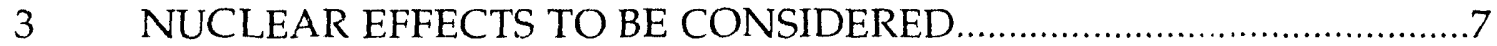

$4 \quad$ VALIDATION TESTING CONCEPTS..................................................10

5 SOS SV PROTOCOL SIMULATION CODE ISSUES ..............................15

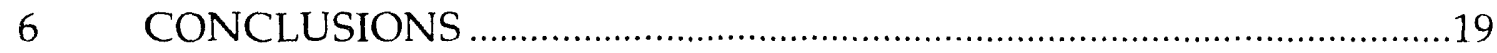

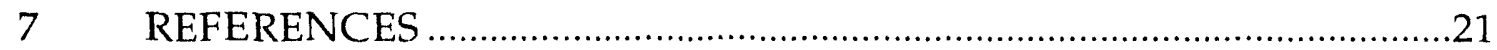




\section{SECTION 1}

\section{INTRODUCTION}

The purpose of this paper is to illuminate the various issues concerned with the development of a nuclear survivability validation (SV) protocol for a system-ofsystems (SOS). We consider these issues in the context of a battle management command, control, and communications $\left(\mathrm{BMC}^{3}\right)$ network in the form of the Hypothetical System Architecture (HSA) described below. At the SOS level, the highest possible level of integration (LOI), survivability validation will require a combination of software and hardware tools. The SV protocol must validate the nuclear survivability of the $\mathrm{BMC}^{3} \mathrm{SOS}$, which involves considering the combined susceptibilities of both the SOS platforms and the communication links.

A survivability validation protocol is a pre-defined, ordered set of tools and procedures which must be applied to a specific object to validate, with a measurable statistical confidence, the capability to perform a specified mission function in a defined environment resulting from a specified threat class. Asplication of the protocol produces a documented collection of data establishing auditable traceability through the system SV process. The protocol must include detailed prescriptions for the combination of validation tests, simulations, and analyses required to exercise the SOS in order to show that it is survivable in a nuclear engagement, regardless of individual platform or link susceptibilities.

A survivability regimen is a set of survivability validation protocols required to assure the specified performance of the system for its validated threat. The survivability regimen would be defined in the Test and Evaluation Master Plan (TEMP) by the Program Management Office and approved by the acquisition authority at Milestone I. However, changes to the TEMP during the system lifecycle may require refinement to the regimen to accommodate those changes.

The BMC 3 SOS protocol/regimen builder is the "user" of products developed by technologists familiar with the test and analysis of systems. Both the user and the technologist currently have problems developing and applying survivability validation protocols at this level of integration. The problem for the technologist is that, for the SOS level in particular, the tools that he would use to create the protocols are not well enough developed or available for practical use. For example, there really are no facilities available for SOS testing, as there are for lower levels of integration. The problem facing the "user" is the complete absence of survivability validation protocols at the SOS level.

During the development of the $\mathrm{BMC}^{3} \mathrm{SV}$ regimen, engagement scenario simulations will be used to determine quantitative requirements to be levied on the platforms comprising the SOS. The engagement scenario simulations will ideally be part of requirements generation process. These simulations may be considered part 
of the regimen because, at the SOS level, the survivability strategy must consider the means of validating survivability at the outset. The SV protocols for the lower levels of integration will either validate that the platforms meet requilements or wiil determine the attained survivability levels, which may be higher or lower than the requirements.

Survivability is, of course, not necessarily attained only through hardness. However, the overall $\mathrm{BMC}^{3}$ regimen incorporating all lower level protocols, will involve selected hardness requirements. That is, certain platforms, subsystems, components, and parts will be hardened to withstand some specific level of relevant nuclear environments. The hardness level will be determined by standard effects balancing considerations based on engagement scenarios performed earlier in the life cycle. It is plausible, for example, that survivability of the SOS/BMC ${ }^{3}$ will be attained by requiring ground-based, air-based and sea-based platforms to be hardened to a High Altitude Electromagnetic Pulse (HEMP) specification, while achieving survivability to all other prompt and persistent effects through redundancy, avoidance, maneuverability, reconstitution, etc. Protocols at lower LOIs, which are part of the regimen, would then involve characterizing the survivability performance (and degradation) via effects testing. The test results could then be provided to those executing the SOS-level protocol to use in simulations and tests at the SOS level.

The following sections will discuss the Hypothetical System Architecture, the nuclear effects that must be modeled in the simulation, validation test concepts to be considered, the validation/pedigree of the nuclear environments and effects models/codes, and other SOS SV protocol simulation code issues. The concluding remarks highlight the most likely way of simulating nuclear effects and the continued need for a configuration control program for simulation tools. 


\section{SECTION 2}

\section{HYPOTHETICAL SYSTEM ARCHITECTURE}

The HSA that will be used to illustrate a complex SOS is a generic BMC ${ }^{3}$ system. It contains air-, space-, sea-, and land-based components as shown in Figure 2-1. Table 2-1 coritains a short description of the various links and platforms that are represented in the HSA. The mission of the HSA is to detect, track, and, upon command, intercept and destroy by non-nuclear means, at leas ${ }^{*} X \%$ of up to $Y$ incoming ICBM/SLBM re-entry vehicles (fired singly, rippled, or in salvo), with an associated confidence of $\mathrm{C} \%$. The system must survive and operate in a nuclear environment. The definition of nuclear survivability, per DoDI 5000.2 (and DoD Dir 5000.1), is "the capability of a system to avoid or withstand man-made hostile environments without suffering an abortive impairment of its ability to accomplish its designated mission."

During HSA operation, the flow of information is from one or more of the space-based launch sensors to one or more of the communications satellites. These, in turn relay the information between satellite platforms and the respective surface and airborne sites (North American Air Defense Command (NORAD), trackers, interceptor control center, Airborne Command Post $(A B C P)$, and various sea platforms). The information from the space-based mid-course tracker flows along the same path. Information from the sea and ground platforms is fed into the central command facility (which in this case is NORAD). Command and Control information flows from the central command facility to the sensor and command sites. Once the launch decision is made the interceptor control center communicates with the ground-based final tracker, NORAD, and the interceptor to guide the interceptor to its target.

Each platform will be assumed to have been subjected to its own SV protocols. This means that the protocol for the SOS will probably require the use of an SOS simulator which will request survivability information from subordinate platform protocols. For some of the platforms (such as the Airborne Communications Node, Ground-Based Final Tracker, etc.), a functional test simulator may be used to assess the platform operation in the presence of normal or nuclear environments. It is assumed that any such individual system simulators will have been validated for normal operational environments and that each will adequately stress the system under normal operating conditions. A nuclear environment simulator may consist of these basic simulators modified to include nuclear effects. 


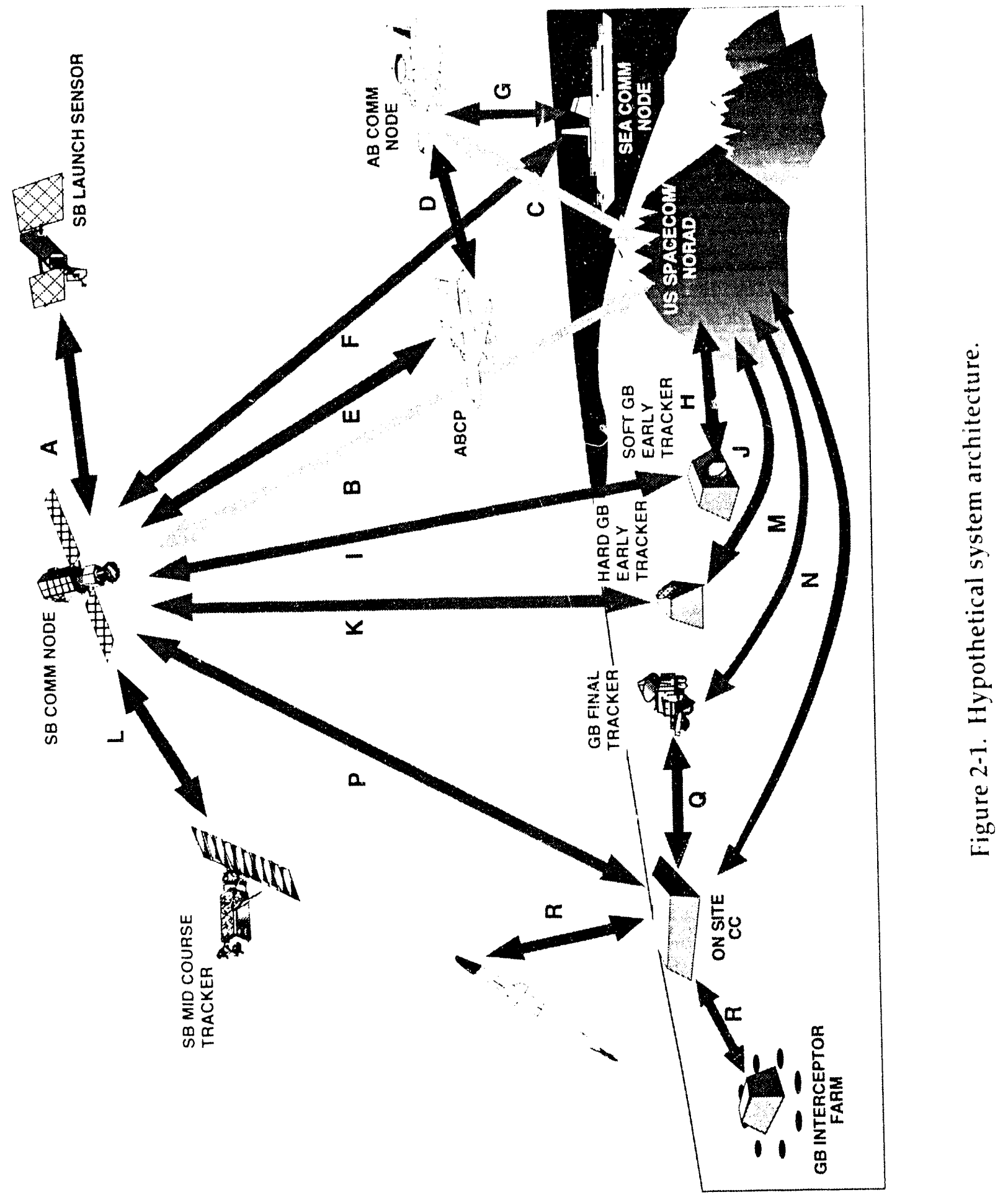




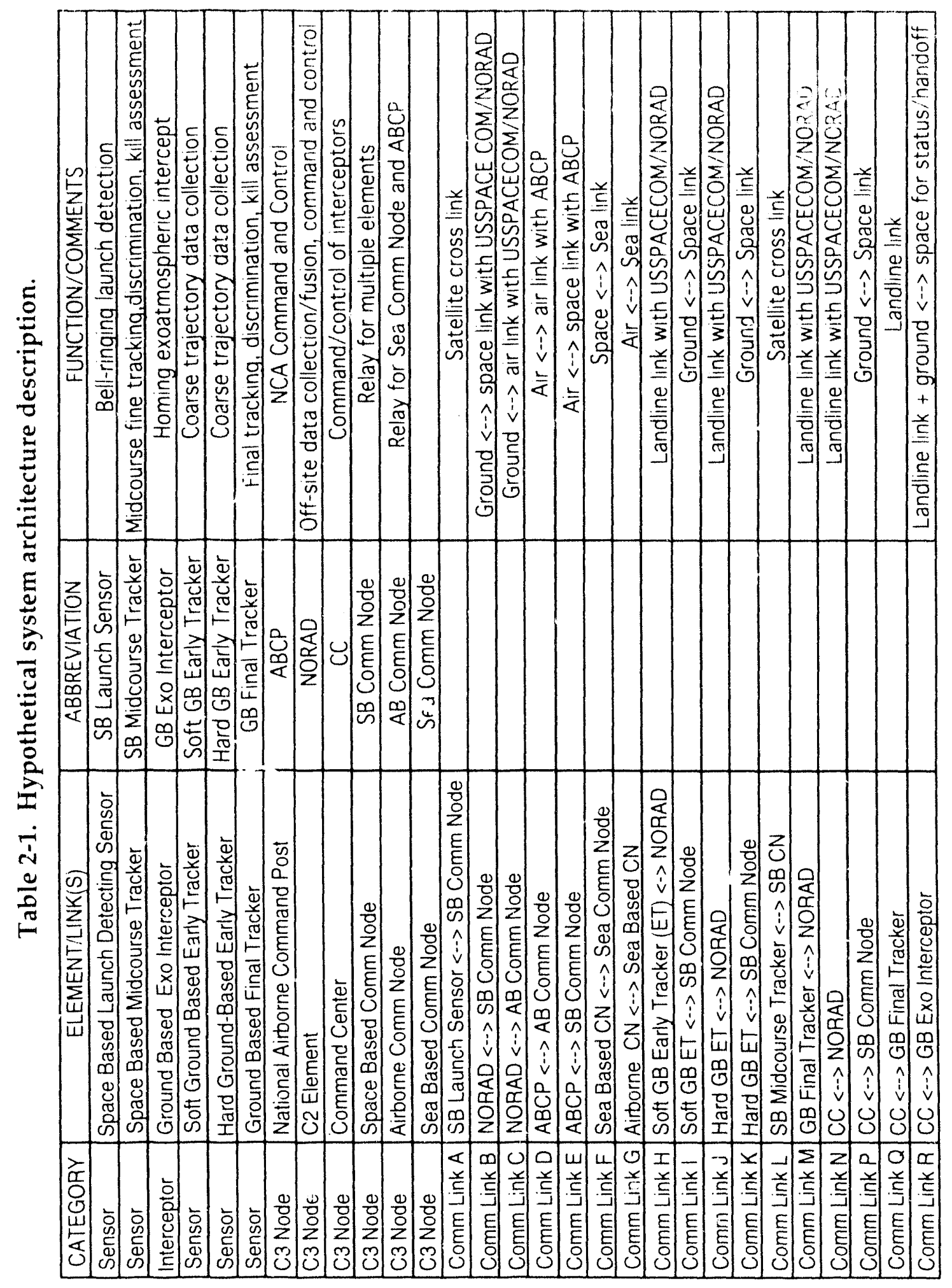


There may have to be an additional computer for the nuclea: simulation management. This simulation management system would coordinate the simulated attac' burst locations and times, and turn on any hybrid simulations at the proper times and levels (e.g., link simulators, scene generators). A hybrid simulation is defined as a simulation that includes hardware and/or man-in-theloop in addition to software. This approach requires that the potential effects of nuclear bursts on all of the platforms and links in the architecture must be modeled, or represented in some fashion. However, due to the many possible engagement scerarios and associated ranges of environments involved, the simulation must be able to parametrically inject the effects of the nuclear environment on each platform to determine if it is destroyed, degraded, or fully operational. If a particular platform or link is not able to perform its function, then the simulation should verify that the SOS is adequately re-configured to perform its mission. 


\section{SECTION 3}

\section{NUCLEAR EFFECTS TO BE CONSIDERED}

The HSA described above involves platforms deployed in many different altitude regimes, and thus rarious SOS platforms can be exposed to both endoatmospheric and exoatmospheric nuclear bursts. These environments contain both prompt and persistent components which could degrade the individual platform's capabilities and performance, and yet allow the overall SOS to survive the nuclear scenario and complete its mission.

The prompt environments generally pose a damage (or upset) concern to the platforms that comprise the SOS, while the persistent environments pose both damage/upset as well as operability (signal-to-noise) problems. Both must be addressed in the SV protocol at the SOS level, but it will generally be true that real iests (hardware simulations) of the actual $\mathrm{BMC}^{3}$ system will only test operability since we cannot afford to permanently damage any portion of it in a test; actual damage causing environments and effects must be investigated and characterized at lower levels of integration. These damage-causing effects can be represented in hardware-in-the-loop tests through the use of software simulations of selected platforms (for example, in an algorithm that removes the platform from the SOS when a simulated nuclear environment level is above a specified threshold).

There are some nuclear environments that are well understood and that have well characterized nuclear effects; for example, those prompt environments and effects which can be studied in underground effects and device tests. By contrast, there are some environments and effects that are not as well understood due to limited or non-existent data; this tends to be the case with persistent environments, where nuclear tests are not possible.

The potential susceptibilities to nuclear effects/environments considered in this section are for illustrative purposes only. However, they are typical of the matrix of potential s'usceptibilities that must be identified and documented to develop a protocol for an $\mathrm{BMC}^{3}$ SOS. The SV protocol must consider these potential susceptibilities, and must exercise them in tests and simulations to validate survivability of the SOS. The selected environments illustrate the scope of the nuclear environment effects that must be considered when validating the survivability of a system-of-systems.

Per DoD Instruction 5000.2, susceptibility is defined as "the degree to which a device, equipment, or weapon system is open to effective attack due to one or more inherent weaknesses. Susceptibility is a function of operational tactics, countermeasures, probability of enemy fielding a threat, etc. Susceptibility is considered a subset of survivability." 
Thus susceptibility refers to the potential for damage or degradation in a platform or link due to an effect or an environment. For example, if it can be argued that an $\mathrm{rf}$ communication link will be affected by a nuclear disturbed environment in the form of a high electron density, then that link is potentially susceptible to nuclear disturbed electron densities. It follows that the SV protocol must consider this effect/environment in its validation of nuclear survivability. This view recognizes that there are some effects/environments which do not pose threats, and hence do not have to be considered in any tests or simulations within the SV protocol. Examples would be those that can be immediately dismissed such as electromagnetic pulse (EMP) on geosynchronous satellites, $\mathrm{X}$-ray effects on ground systems, or other effects that can be shown to be entirely insignificant through analysis. The point is that, if an environment/effect has an entirely negligible effect, it need not be included iri any protocol simulations or tests. This is in accord with conventional hardening protocols at lower levels of integration, where tests and detailed modeling/computer simulations are only done on aspects that there is reason to believe (based on analysis by experts) are important, i.e., on potential susceptibilities.

The individual platforms and links of the HSA $/ \mathrm{BMC}^{3}$ are assigned susceptibilities to endoatmospheric and exoatmospheric nuclear environments as presented in Table 3-1, where considerations were given to both vulnerability (damage and upset) and operability (system operation in the presence of nuclear disturbances). To validate the survivability of an SOS, nuclear environments and effects to which the SOS's links and nlatforms are susceptible must be considered. Hardness of the platforms to specified environments or effects (Electromagnetic pulse, transient radiation effects on electronics, thermo-structural response, etc.) is assumed to have been validated in protocols at lower levels of integration. Platform susceptibilities are of course not limited to cases where platform deployment altitude and burst altitude are comparable; that is, some platforms with an endoatmospheric basing mode may experience some exoatmospheric environments. For example, ground- and sea-based platforms are susceptible to HEMP environments as specified in the DOD-STD-2169A. In this example, we consider communication links consisting of land line links to be susceptible to grounc motion, but not EMP or gamma dose rate (i.e., rf and gamma shielded lines are assumed). 


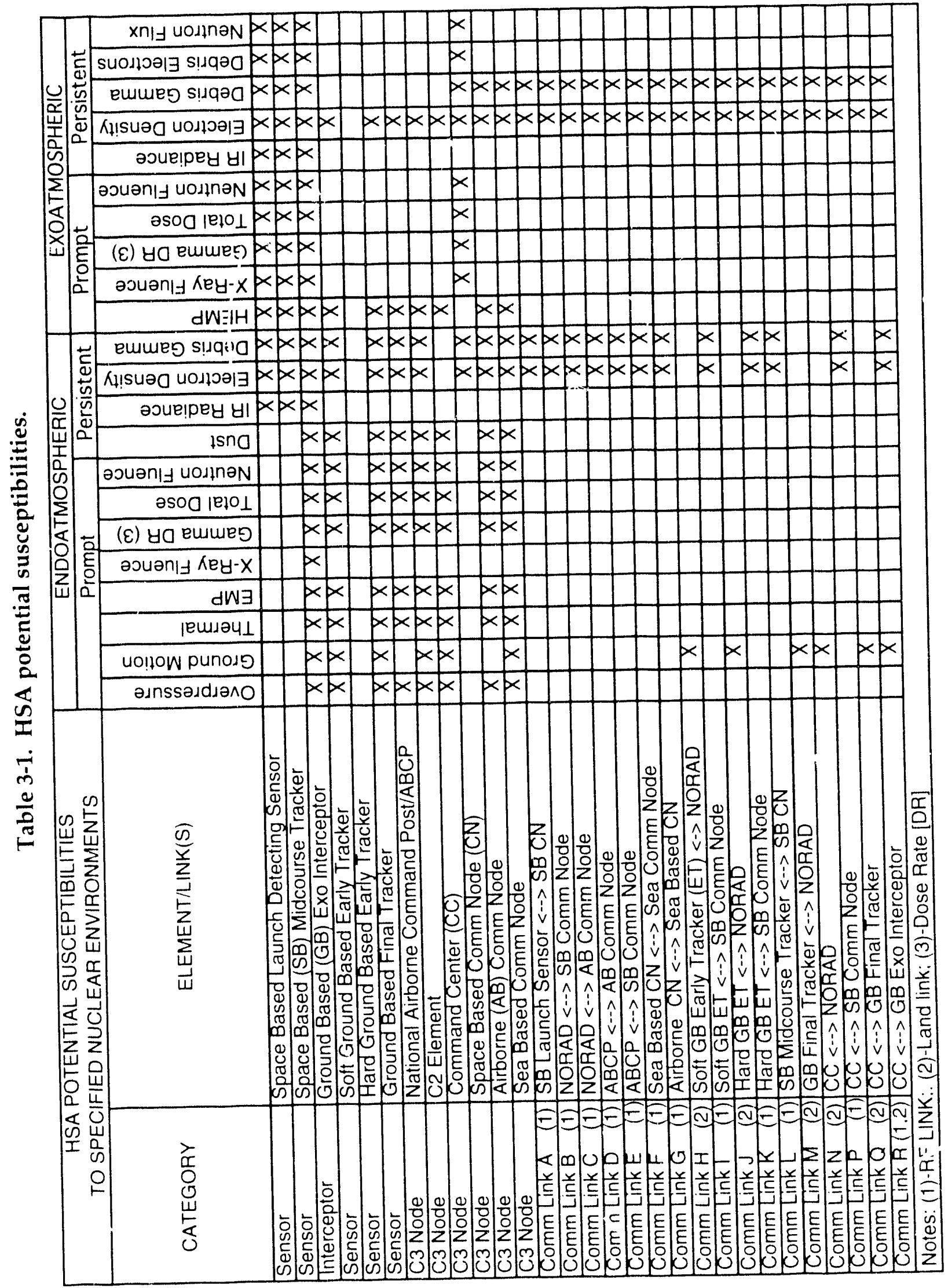




\section{SECTION 4}

\section{VALIDATION TESTING CONCEPTS}

Here we consider prospective test concepts that apply at the SOS level. There are several considerations peculiar to this level of integration:

- Unlike platform and lower levels of integration, the SOS is not portable in any sense, since it involves "buildings" or other permanently installed ground-based platforms.

- It is extended in space so that not all of the platforms experience the same nuclear environment (unlike the case for platforms, there is no nuclear environment that is externally uniform over the SOS). As a result, there are many combinations of possible environments.

- SOS nuclear survivability must be referenced to a range, or variety, of possible engagement scenarios, rather than in terms of hardening to a range of possible point environments (as it is for platforms, where a range of environments or requirements, or "specs", "flow down" from earlier SOS simulations).

- An actual test modeling a real nuclear environment is not possible (as it is for some lower levels, where underground nuclear tests (UGT's) can be used, assuming they remain a testing option).

Survivability to some effects is implemented at lower levels of integration in the form of hardness to some specified threat (which early in the development phase is a requirement that "flows" down from engagement scenarios at the SOS level). An example would be HEMP, where hardness to HEMP is still required as the way to achieve survivability to this environment. Other environments may not require hardening, however, but may require other methods. We emphasize that survivability can be attained by methods other than hardness. DoDI 5000.2 emphasizes the need to consider and implement, when most cost effective, other methods such as proliferation, redundancy, reconstitution, avoidance, deception, active defense, and tolerance to the effect. For those environments/effects where a hardness requirement is involved, lower level SV protocols must validate that this required hardness level was in fact attained. We may still view this as a platform susceptibility, but only for stresses (or levels) in excess of the requirement. For environment levels above the requirement, SV protocols might involve tests or simulations where the platform is regarded to fail for levels above the requirement. For example, a "cookie cutter" module for incorporating prompt nuclear effects in a system simulation is illustrated in Figure 4-1. This is similar to the simulation concept in Riley et al., 1991. A generalization to include persistent effects may also be possible, but poses difficult timing problems. Alternatively, if the lower level protocols involved evaluating or characterizing the performance degradation for levels above specifications, then degradation or fragility curves could be used in any tests or simulations specified in the SOS protocol. 


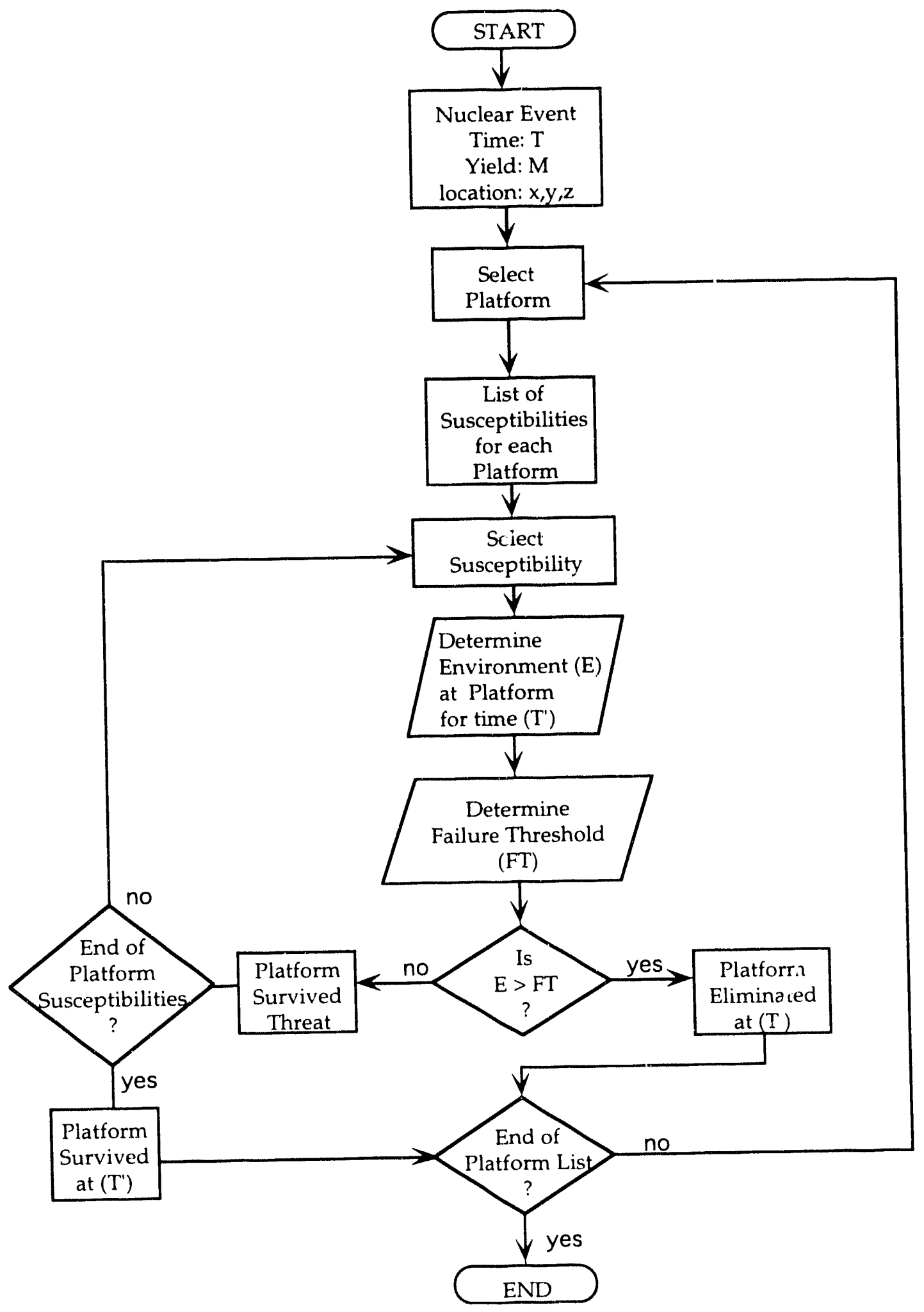

Figure 4-1. Prompt effects module. 
It is clear from these considerations that validation testing will be quite difficult and will pose special problems at the SOS level. The general categories of tools that may be available for application in any SOS SV protocol will consist of :

(1) Software simulations.

(2) Scene generators and link simulators.

(3) Special hardware that can be airborne or space-based to simulate nuclear disturbed atmospheric conditions/effects.

(4) Special hardware/computers/software packages or models used to exercise portions of the SOS.

(5) Special hardware and procedures to represent a specific nuclear effect/ environment.

Category (1) refers to purely computer simulations of the SOS, wherein a wide variety of engagements and combinations of environments can be ccisidered. This tool corresponds, for example, to "level 2" of the National Test Bed (NTB) simulator, where SOS survivability is validated. It is to be distinguished from the "level 1" simulations, where hardness/balancing is considered to derive requirements on platforms, subsystems, etc.

Category (2) refers to special purpose hardware and software that simulate disturbed environments for radar, communication links, and optical sensors. Thus target acquisition, discrimination, communication, etc., can be exercised in the complicating presence of nuclear disturbances (which generally cause signal-to-noise or operability problems). Designers of the Safeguard system, for example, planned to use a system exerciser to drive the radar (at an injection point beyond the phased array elements) to simulate battle engagements. Another example is the Strategic Defense Command (SDC) Portable Radiation/Redout Testbed for Sensors (PORTS) test concept, which is an end-to-end test of an optical sensor subsystem. The hybrid simulation concept is illustrated in Figure 4-2, where the "balloons" connected to the platforms via "bubbles" represent software driven simulations. In this illustration, we have considered a Ground-Based Exoatmospheric Interceptor (GBEI) platform to be replaced by a launch/fly out simulation; we have also depicted each of the air, sea, and land-based platforms as subjected to some degree of simulated nuclear environment.

Category (3) refers to such things as barium rocket canister techniques, where the atmosphere is actually ionized to some extent, just as it would be from a nuclear burst. Metallic reflectors placed within the atmosphere to interfere with radio transmission to simulate a nuclear disturbed atmosphere would be another example. Of course, it is clear that a number of difficult simulation fidelity problems will be posed by any of these techniques. Also, the cost may be prohibitive. Moreover, based on recent discussions with the Defense Nuclear Agency's Atmospheric Effects Division (DNA/RAEE), the barium canister technique appears to generate inadequate ionization to interfere with an $\mathrm{rf}$ link. 


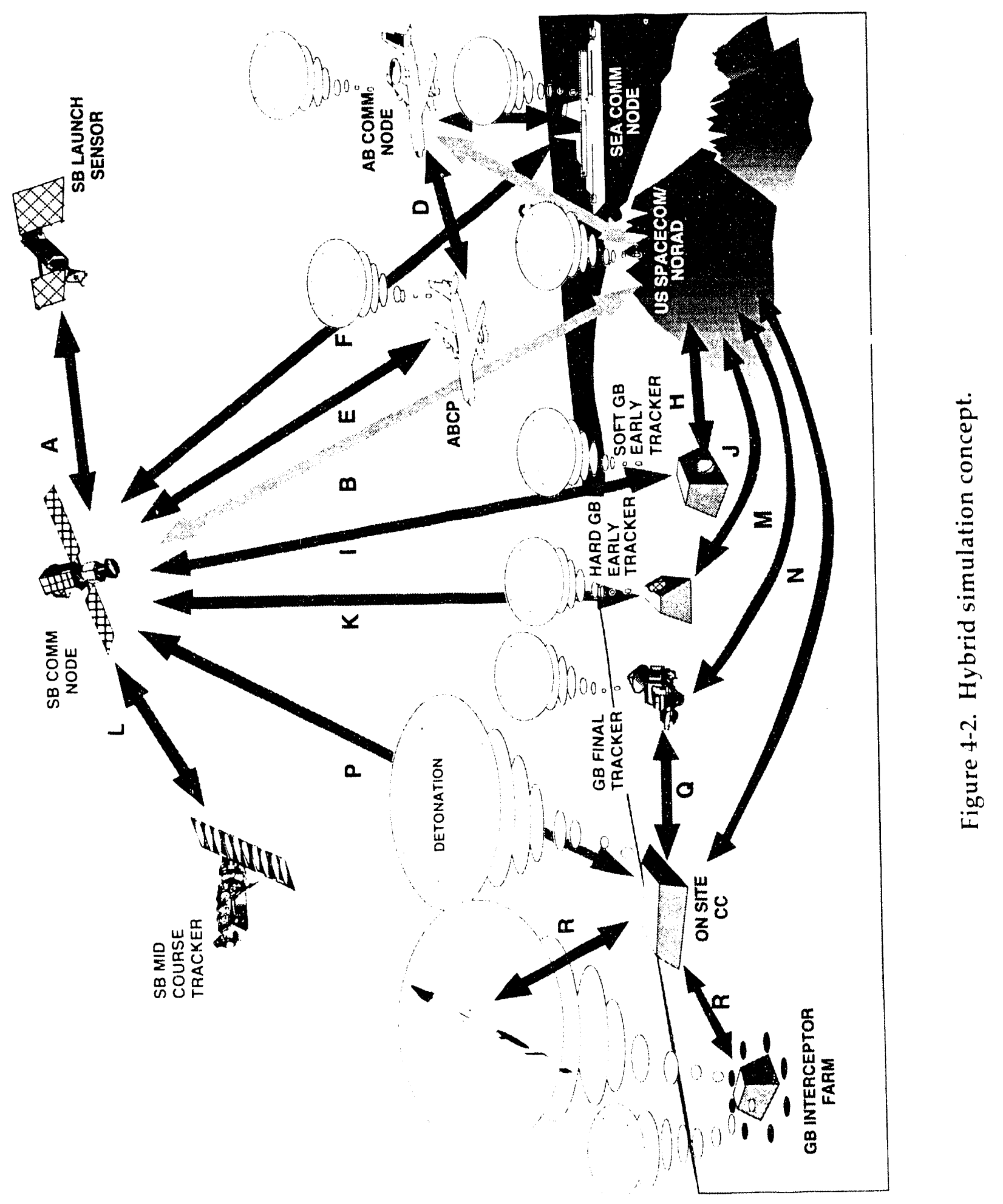


Category (4) refers to special hardware and software, such as auxiliary computer networks, that would exercise portions of the system, or perhaps replace specific platforms. For example, the Ground-Based Exoatmospheric Interceptor (GBEI) $/ C^{2}$ interface in our HSA could be simulated by a special GBEI flight simulator software package.

Category (5) refers to such things as blast simulations or current injection devices, to simulate the effect of a degrading nuclear environinent (e.g. air blast or EMP). It is, of course, assumed for the SOS SV protocol that protocols at platform and lower levels of integration have already been executed to validate (or quantify) survivability/hardness of that particular platform. Thus, it would not make sense in category (5), to use actual damage-causing levels of an effect/environment (since we cannot afford to break, or damage, an expensive SOS), but reversible degradation could conceivably be included. An example of this category is the use of current injection into a $C^{3}$ facility to exercise its response mechanisms.

Another salient point regarding the above categories of tools is that while they can apply throughout the lifecycle of the system, some may be mor a applicable to certain lifecycle phases than others. Category (1) can and should be used to validate survivability early in the development phase, where the SOS is in the design/planning stage. However, category (1) will continue to be important throughout the development phase, as it allows the most flexibility, the most extensive and varied tests, and is the least expensive kind of simulation. Categories (2) through (5), on the other hand, assume that portions of the SOS actually are built and available for testing, at least in the form of prototypes.

Another point is that validation of the fielded SOS (deployment pnase) is something that can be continued with the system exerciser concept. A system exerciser capability could be tailored to validate survivability and "ar ailability" (readiness) periodically throughout an SOS deployment. This is an extension of the hardness maintenance/hardness assurance concept for platforms and subsystems. 


\section{SECTION 5}

\section{SOS SV PROTOCOL SIMULATION CODE ISSUES}

As alluded to earlier in this paper, the prospect of testing a complex SOS in an actual nuclear environment short of a nuclear war is non-existent. Thus, the highest confidence approach to an SOS protocol will probably involve some combination of software simulations and hybrid simulations, where hybrid simulations are combinations of software, hardware, and man-in-the-loop used in concert to provide the desired simulation.

Computer codes could be used in both purely software simulations as well as hybrid simulations. The relevant codes at the SOS level will be used to

(1) Calculate prompt environments (gamma, X-ray, EMP, blast, etc.) on the various platforms for a given simulated burst location,

(2) To calculate persistent environments on a global scale, and

(3) To calculate effects of the persistent environments on links, radar, and sensors.

These persistent effects involve blackout, redout, and clutter. They generally pose signal-to-noise problems, and hence their effects can also be hardware simulated with computer code-driven scene generators and link simulators for example. One would probably not use codes at the SOS engagement level to calculate prompt damage/upset effects, as these would be characterized off-line and in lower level protocols (either in terms of pass/fail or degradation).

Codes of the types described in Table 5-1 have dealt with some of these issues (Faizullabhoy, 1992). This table shows some examples of codes that would be used to calculate prompt environments, persistent environments, and persistent effects. Our assessment of the status of the validation and documentation is also indicated in the table. Codes of this type could either be combined as subroutines into the simulation software, or will have to be represented in the form of off-line generated lookup tables or other types of data bases.

One major issue in any $\mathrm{BMC}^{3}$ simulation will be the following: what parameters have to be specified in a nuclear engagement. For example, are burst location, yield, and time sufficient to define the environment and effects? In particular, what does the time parameter mean? Is it relative to SOS phases, or are there state-of-the-universe parameters as well (solar storms, sun and moon shine, $\mathrm{day} / \mathrm{night}$, location of supporting or synergistic military systems or forces, etc.). The identification of parameters that are of concern to SOS operations is one of the problems confronting the simulation developer.

Another of the dificicult problems facing both the protocol and simulation designer is that of code validation, whether the code is true to the real world. The plain fact is that, since we cannot do above-ground (AG) nuclear tests, there is no 
Table 51. Examples of computer codes for SOS SV protocol.

\begin{tabular}{|c|c|c|c|c|}
\hline & & \multicolumn{2}{|c|}{ Validations } & \multirow[b]{2}{*}{ Documentation } \\
\hline Code & Brief Description & $\begin{array}{c}\text { Comparison with } \\
\text { other codes and } \\
\text { analysis }\end{array}$ & $\begin{array}{l}\text { Comparison to } \\
\text { Experimental } \\
\text { Data }\end{array}$ & \\
\hline PEM & $\begin{array}{l}\text { Engagement level code for predicting } \\
\text { nuclear effects }\end{array}$ & $\begin{array}{l}\text { Yes, based on } \\
\text { NORSE } \\
\text { comparisons * }\end{array}$ & $\mathrm{No}$ & Available* \\
\hline MICE & $\begin{array}{l}\text { A first principles code for calculating } \\
\text { the evolution of high-beta plasma in } \\
\text { an surrounding fireball and/or kinetic } \\
\text { energy patch regions created by high } \\
\text { energy explosions }\end{array}$ & Yes** & Yes** & $\begin{array}{l}\text { Technical } \\
\text { reports* }\end{array}$ \\
\hline MELT & $\begin{array}{l}\text { A first-principles code for calculating } \\
\text { the evolution of "low-beta" plasma in } \\
\text { and surrounding "late-time" fireball } \\
\text { kinetic energy patch plasma that has } \\
\text { evolved into "high-altitude nuclear- } \\
\text { burst plume." }\end{array}$ & Yes** & $\begin{array}{l}\text { Yes, but } \\
\text { limited * }\end{array}$ & $\begin{array}{l}\text { Technical } \\
\text { Reports* }\end{array}$ \\
\hline NORSE & $\begin{array}{l}\text { Nuclear Optical and Radar Systems } \\
\text { Effects; state-of-the-art system } \\
\text { effects code, intermediate between } \\
\text { first-principles physics approach and } \\
\text { fast-running codes used in } \\
\text { engagement simulations }\end{array}$ & ' $\cos ^{* *}$ & $\begin{array}{l}\text { Yes, for } \\
\text { component } \\
\text { models ** }\end{array}$ & Yes** \\
\hline HISEMM & $\begin{array}{l}\text { A FORTRAN callable module for use in } \\
\text { global engagement simulations. } \\
\text { Calculates RF and IR propagation } \\
\text { efforts in a multiburst nuclear } \\
\text { environment }\end{array}$ & $\begin{array}{l}\text { Yes, based on } \\
\text { NORSE, and } \\
\text { SCENARIO } \\
\text { comparisons* }\end{array}$ & No & Yes** \\
\hline SCENARIO & $\begin{array}{l}\text { A physics-based engineering } \\
\text { simulation tool for disturbed } \\
\text { environments resulting from multiple } \\
\text { high-altitude nuclear explosions }\end{array}$ & Yes** & Yes** & Yes" \\
\hline WECOM & $\begin{array}{l}\text { A family of codes for calculating } \\
\text { effects of normal, nuclear, and } \\
\text { jamming environments on comm link } \\
\text { performance }\end{array}$ & Yes* & Yes* & Yes** \\
\hline SIMBAL $\|$ & $\begin{array}{l}\text { A fast-running code for predicting } \\
\text { nuclear weapon-produced propagation } \\
\text { effects on individual VLF, LF, and HF } \\
\text { links in large communications } \\
\text { networks }\end{array}$ & Yes $^{*}$ & Yes* & Yes** \\
\hline
\end{tabular}


way to rigorously validate the persistent environment codes. True, there are AG data from the 1950s and 1960s, but these tests were uncontrolled and the data are really quite limited. Also, normal environments can be used to provide a degree of validation. As pointed out in Hodges et al., 1992, a code that cannot be validated can still be useful; however, care must be taken that the code includes state-of-the-art physics models that represent the complete ensemble of effects.

A less serious problem, but one that should be mentioned, is code documentation. Some of the potentially useful codes are not formally documented. A related problem is the user friendliness of the code. Also, the simulation fidelity versus run time consideration is a concern. It will undoubtedly be necessary to compromise on high fidelity to get reasonable real-time responses. (Stringer et al., 1992)

The last issue to be discussed is that of configuration control of the SOS simulation tools. Paragraph 2.a, Policies, on page 6-F-2 of DoDI 5000.2 states: "The survivability of all systems that must perform critical functions in a man-made hostile environment shall be an essential consideration during the acquisition life cycle of all programs, to include developmental and non-developmental programs."

The next paragraph in this reference states that survivability from all threats (including nuclear) found in the various levels of conflict shall be considered. As a result, nuclear survivability is to be considered as part of the mission needs statement. Hence, the argument can be made that th: tools used to validate the system survivability should be brought under the same kind of configuration control as mission critical items.

For example, the Department of Defense has developed a set of standards to ensure that Mission-Critical Computer Resources (MCCR) software is developed with the necessary rigor. These standards include:

(1) DoD-STD-2167A, Defense System Software Development, 29 February 1988.

(2) DoD-STD-2168, Software Quality Evaluation

(3) MIL-STD-483, Configuration Management Practices for Systems, Equipment, Munitions, and Computer Programs, 4 June 1985.

(4) MIL-STD-1521B, Technical Reviews and Audits for Systems, Equipment, and Computer Programs, 4 June 1985

DoD-STD-2167A is the most important of these standards. It specifies the products to be produced during software development, requirements to be satisfied by the development process, and reviews to be performed. The iifecycle phases, deliverable products, reviews, and baselines are discussed in the standard. These products are intended to provide traceability throughout the lifecycle. Baseline products cannot be arbitrarily changed without undergoing strict configuration management practices. Software testing mandated by the standard is fairly 
comprehensive, and following the practices of this (and other) standards can lead to more reliable software. 


\section{SECTION 6}

\section{CONCLUSIONS}

The previous sections have discussed the various issues involving the development of an SOS protocol. Based on those issues, the following are a few conclusions regarding the development of such a protocol.

(1) It appears likely that the SOS protocol will have to rely mainly on computer simulations, with some assistance from hybrid simulations which involve some of the platforms, links, and man actually being "in the loop" (hardware-in-the-loop and man-in-the-loop). These hybrid simulations will involve link simulators and scene generators (for optical sensors and for radar, to simulate "redout" and "blackout" respectively). A serious drawback that seems inescapable at the present time is that none of the actual nuclear environments can be present "in actuality" in tests in SV protocols at the SOS level. This may be at odds with DoD directives which require that survivability validation not be based solely on analysis. (One can argue that computer simulation is purely analysis; furthermore, hybrid simulation is to a large extent based on analysis, since the scene or disturbed atmosphere is based on a calculated or modeled environment.) Runtime and simulation fidelity tradeoffs will be a major consideration, made more difficult by the fact that many modeled features of the persistent environment will not be amenable to validation.

(2) The hybrid simulation/system exerciser concept can also be of use demonstrating that fielded systems retain their initial survivability (the goal of hardness maintenance/hardness surveillance). A general coricern in military systems is that, while they might be survivable when initially fielded, they may not retain this survivability as the system ages. This concern could also arise in connection with an SOS/BMC ${ }^{3}$. With a testability feature designed into the system, in the form of a hybrid simulation capability at the SOS level, the simulation feature could serve a dual purpose: to validate survivability in the beginning of the deployment phase as well as during deployment.

(3) At the present time, there appears to be little hope of physically simulating disturbed environments using non-nuclear techniques. Even if such techniques were available, it may be desirable to use them off-line to validate software tools which would then be used in SOS simulations.

(4) Configuration control of the SOS simulation tools should be considered as if the simulation tools were mission critical. For example, simulation software could be treated in the manner described in the previous section with the nuclear effects software conforming to the requirements of the military standards, such as DoD-STD-2167A and 2168. In addition, the nuclear effects simulation hardware could conform to the comparable mission critical hardware standards for 
documentation, verification, and validation. As a result, DNA should consider controlling the simulation tools as mission critical. 


\section{SECTION 7}

\section{REFERENCES}

"Defense Acquisition (U)," DoD Directive 5000.1, February 1991. (UNCLASSIFIED)

"Defense Acquisition Management Policies and Procedures (U)," DoD Instruction 5000.2, February, 1991. (UNCLASSIFIED)

Faizullabhoy, A., "DNA Nuclear Weapon Effects Code Catalog (U)," DASIAC, Kaman Sciences Corporation, Santa Barbara, CA, SR-92-001, 24 June 1992. (UNCLASSIFIED)

Hodges, J. and Dewar, J., "Is It You or Your Model Talking? A Framework for Model Validation (U)," Rand, R-4114-AF/A/OSD, 1992. (UNCLASSIFIED)

Riley, W. and Berggren, S.R., "Nuclear Environmental Modeling: The Challenge in End-to-End Computer Simulations of the Strategic Defense System (U)," 1991

Summer Computer Simulation Conference, July, 1991. (UNCLASSIFIED)

Stringer, T.A., Book, P.S., and Rodvold, D.M., "Simulation Fidelity Issues for Nuclear Survivability Validation Protocols (U)," Kaman Sciences Corporation, DNA-TR-92-84, November, 1992. (UNCLASSIFIED) 


\section{DISTRIBUTION LIST}

DNA-TR-93-62

NATO

AAFCE/OOST

ATTN: SQNLDR MULLIGAN

ARTILLERIE KCMMANDO 3

ATTN: LTC JOACHIM BURTH

ATOMIC WEAPONS ESTABLISHMENT, FOULNESS ATTN: DR DARYL LANDEG

SIEMIENS PLESSEY DEFENCE SYSTEMS ATTN: HENRY CHESTERS

TARGETS BRANCH

ATTN: ITTI

USECOM

ATTN: ECJ3-FC

2 CY ATTN: ECJ4-LW

ATTN: ECJ5-N

ATTN: ECJ6-T

ATTN: MAJ FLEMING

\section{DEPARTMENT OF DEFENSE}

ARMED FORCES STAFF COLLEGE

ATTN: C3-JCEWS

ATTN: JCEWS-C3D

ASSISTANT SEC OF DEF (C3I) ATTN: J BAIN

ASSISTANT TO THE SECRETARY OF DEFEINSE ATTN: DR BIRELY ATTN: LTCOL M CRAWFORD

BALLISTIC MISSILE DEFENSE ORGANIZATION ATTN: DA DR GERRY

DEF RSCH \& ENGRG

ATTN: DIR TEST FACILITIES \& RESOURCES ATTN: DEP DIR TEST EVAL.

DEFENSE ADVANCED RSCH PROJ AGENCY ATTN: ASST DIR ELECTRONIC SCIENCES DIV ATTN: DEP DIR RESEARCH ATTN: DIR DEFENSE SCIENCES OFC

DEFENSE COMMUNICATION AGENCY ATTN: COMMAND CENTERS ENG DIR

DEFENSE ELECTRONIC SUPPLY CENTER ATTN: DESC-E

DEFENSE LOGISTICS AGENCY ATTN: DLA-F ATTN: DLA-OE ATTN: DLA-QES ATTN: DLA-SCC ATTN: DLA-SCT ATTN: DLSMO

DEFENSE NUCLEAR AGENCY ATTN: DFRA JOAN MA PIERRE ATTN: RAEE
ATTN: RAEV

ATTN: SPSD

ATTN: SPSP

ATTN: SPWE

ATTN: TITL

DEFENSE TECHNICAL INFORMATION CENTER ATTN: DTIC-DE ATTN: DTIC/OC

DEPARTMENT OF DEFENSE. ATTN: DEP DIR TEST EVAL

NATIONAL COMMUNICATIONS SYSTEM ATTN: NCS-TS A H RAUSCH

NATIONAL DEFENSE UNIVERSITY AITN: CLASSIFIED LIBRARY

NATIONAL SECURITY AGENCY ATTN: D/DIR ATTN: DDI ATTN: TECH DOC LIB

NET ASSESSMENT ATTN: DIRECTOR ATTN: DOCUMENT CONTROL

OPERATIONAL TEST \& EVALUATION ATTN: DIR/OPER TEST \& EVAL STRAT SYS ATTN: SCIENCE ADVISOR ATTN: DEP DIR/RESOURCES \& ADMIN

STRATEGIC \& SPACE SYSTEMS ATTN: DIRECTOR

ATTN: DRE SEVIN ATTN: DR SCHNEITER

\section{DEPARTMENT OF THE ARMY}

ARMY RESEARCH LABORATORIES ATTN: TECH LIB ATTN: SLCSM-D COL J DOYLE

PATRIOT ATTN: PROJECT MANAGER

RESEARCH \& DEV CENTER ATTN: COMMANDER

SATELLITE COMMUNICATIONS ATTN: PROJECT MANAGER

U S ARMY AVIATION SYSTEMS CMD ATTN: PM AIRCRAFT SURVIVABILITY EQUIP

US ARMY BELVOIR RD\&E CTR ATTN: TECHLIB

U S ARMY LABORATORY CMD ATTN: COMMANDER

U S ARMY MATERIAL COMMAND ATTN: OFFICE OF PROJECT MGT 
U S ARMY MISSILE COMMAND ATTN: PMITO

U S ARMY MISSILE COMMAND ATTN: AMCPM-CC/PM

U S ARMY MISSILE COMMAND ATTN: MAJ R LUSHBOUGH

U S ARMY MISSILE COMMAND ATTN: R LENNING

U S ARMY NUCLEAR \& CHEMICAL AGENCY ATTN: MONA-AD

U S ARMY ORD MISSILE \& MUNITIONS ATTN: ATSK-MS ATTN: ATSK-XO

U S ARMY RESEARCH DEV \& ENGRG CTR ATTN: TECH LIB

U S ARMY SIGNAL CTR \& FT GORDON ATTN: ATZH-CDC ATTN: ATZH-CDM

U S ARMY SPACE \& STRATEGIC DEFENSE CMD ATTN: CSSD-SA-EV ATTN: CSSD-SA-EVR CROWSON ATTN: CSSD-SL ATTN: SFAE-SD-GST-EP BUHRMAN

U S ARMY SPACE STRATEGIC DEFENSE CMD ATTN: CSSD.CS ATTN: CSSD-OP ATTN: CSSD-SA-E

U S ARMY STRATEGIC SPACE \& DEFENSE CMD ATTN: CSSD-H-LS ATTN: CSSD-SD-A

U S ARMY TEST \& EVALUATION COMMAND ATTN: AMSTE-TA-F ATTN: AMSTE-TA-FL TELETSKI

U S ARMY VULNERABILITY ASSESSMENT LAB ATTN: SLCVA-D

USA ELECT WARFARE/SEC SURV \& TARGET ACO CTR ATTN: COMMANDER

\section{DEPARTMENT OF THE NAVY}

DEPARTMENT OF THE NAVY ATTN: DIRECTOR

GPS NAVSTAR JOINT PROGRAM OFFICE ATTN: CHARLES TABBERT

NAVAL AIR SYSTEMS COMMAND ATTN: AIR-5115J GT SIMPSON

NAVAL AVIONICS CENTER ATTN: B/710 F GAHIMER ATTN: B/713 D PAULS

NAVAL POSTGRADUATE SCHOOL ATTN: CODE 1424 LIBRARY
NAVAL RESEARCH LABORATORY ATTN: CODE 5227

NAVAL SEA SYSTEMS COMMAND ATTN: COMMANDING OFFICER

NAVAL SURFACE WARFARE CENTER ATTN: COMMANDER

NAVAL WAR COLLEGE ATTN: CODE E-111

NAVAL WARFARE ASSESSMENT CENTER ATTN: DOCUMENT CONTROL

NAVSEA

ATTN: J SATIN

OPERATIONAL TEST \& EVALUATION FORCE ATTN: COMMANDER

STRATEGIC SYSTEMS PROGRAM ATTN: SP-113 D ELLINGSON

DEPARTMENT OF THE AIR FORCE

AIR FORCE CTR FOR STUDIES \& ANALYSIS ATTN: AFCSASAS ATTN: AFSAASAI

AIR FORCE INSTITUTE OF TECHNOLOGYIEN ATTN: AFIT/ENP COL R TUTTLE

AIR FORCE SPACE COMMAMD (LKI) ATTN: CAPT WEIDNER ATTN: LT D BARRON ATTN: MAJ D ROBINSON

ASSISTANT CHIEF OF STAFF ATTN: AF/SAN

DEPARTMENT OF THE AIR FORCE ATTN: NCGS B HOPKINS

DEPUTY CHIEF OF STAFF/AF-RD-D ATTN: AFIRD-D

DEPUTY CHIEF OF STAFF/AFRDSD ATTN: SAF/AQSD

PHILLIPS LABORATORY ATTN: CAPTIAN LORANG ATTN: PLWS L CONTRERAS ATTN: WSP J DEGAN ATTN: WSPRPETERKIN

ROME LABORATORYISUL ATTN: COMMANDER

SECRETARY OF THE AIR FORCE ATTN: AF/RDSL

SM-ALC DET 25/LXE ATTN: LKNIP MAJ S HOFF ATTN: PCLARTER

SPACE DIVISION(AFSC) ATTN: SSDMZS 


\author{
WRIGHT LABORATORY \\ ATTN: D WATTS \\ DEPARTMENT OF ENERGY \\ DEPARTMENT OF ENERGY \\ ATTN: WALT KELLY \\ DEPARTMENT OF ENERGY \\ ATTN: C MEYERS \\ EG\&G IDAHO INC \\ ATTN: MS ILF-2 \\ SANDIA NATIONAL LABORATORIES \\ ATTN: TECH LIB-PERIODICALS \\ DEPARTMENT OF DEFENSE CONTRACTORS
}

AEROSPACE CORP

ATTN: LIBRARY ACQUISITION

ALFONTE ASSOCIATES

ATTN: WILLIAM ALFONTE

ANALYTIC SERVICES, INC (ANSER) ATTN: LIBRARY

APTEK, INC

ATTN: T MEAGHER

BERKELEY RSCH ASSOCIATES. INC ATTN: J ORENS ATTN: N PEREIRA

BERKOWITZ ENTERPRISES ATTN: HM BERKOWITZ

BOEING AIRCRAFT MARINE ATTN: CHUCK WERTZBERGER

BOOZ ALLEN \& HAMILTON INC ATTN: J KEE

BOOZ-ALLEN \& HAMILTON, INC ATTN: J M VICE

HUDSON INSTITUTE, INC ATTN: LIBRARY

INSTITUTE FOR DEFENSE ANALYSES ATTN: CLASSIFIED LIBRARY ATTN: DR HDICKENSON ATTN: DR LESLIE COHEN ATTN: E BAUER ATTN: GRAHAM MCBRYDE ATTN: I KOHLBERG ATTN: OED W SHELESKI ATTN: R MILLER

JASPER WELCH ASSOCIATES ATTN: MAJ GEN J WELCH
JAYCOR

ATTN: CYRUS P KNOWLES

ATTN: E WENAAS

KAMAN SCIENCE CORPORATION

2 CY ATTN: G BROCK

2 CY ATTN: K IANACONE

2 CY ATTN: T STRINGER

KAMAN SCIENCES CORP ATTN: LIBRARY

KAMAN SCIENCES CORP ATTN: DASIAC

KAMAN SCIENCES CORPORATION ATTN: DASIAC

LOCKHEED AERONAUTICAL SYSTEMS ATTN: CENTRIAL LIBRARY

LOCKHEED MISSILES \& SPACE CO, INC ATTN: VULINERABILITY \& HARDENING

LOGICON R \& D ASSOCIATES ATTN: LIBRARY

LOGICON R \& D ASSOCIATES ATTN: DOCUMENT CONTROL

$M I T$ LINCOLN LAB ATTN: $V$ SFERRINO ATTN: C F WILSON ATTN: R HALL

MARTIN MARIETTA DENVER AEHOSPACE ATTN: RESEARCH LIBRARY

MASSACHUSETTS INST OF TECHNOLOGY ATTN: J RUINA

MCDONNELL DOUGLAS HELICOPTER CO ATTN: B MOORE ATTN K K PIERCE ATTN: W SIMS

MISSION RESEARCH CORP ATTN: DOCUMENT CONTROL ATTN: TECH INFO CENTEA

NICHOLS RESEARCH CORPORATION ATTN: L GAROZZO

RAYTHEON - MSD ATTN: LIBRARY

SCIENCE APPIIICATIONS INTL CORP ATTN: MATKINS

TELEDYNE BROWN ENGINEERING ATTN: P SHELTON 

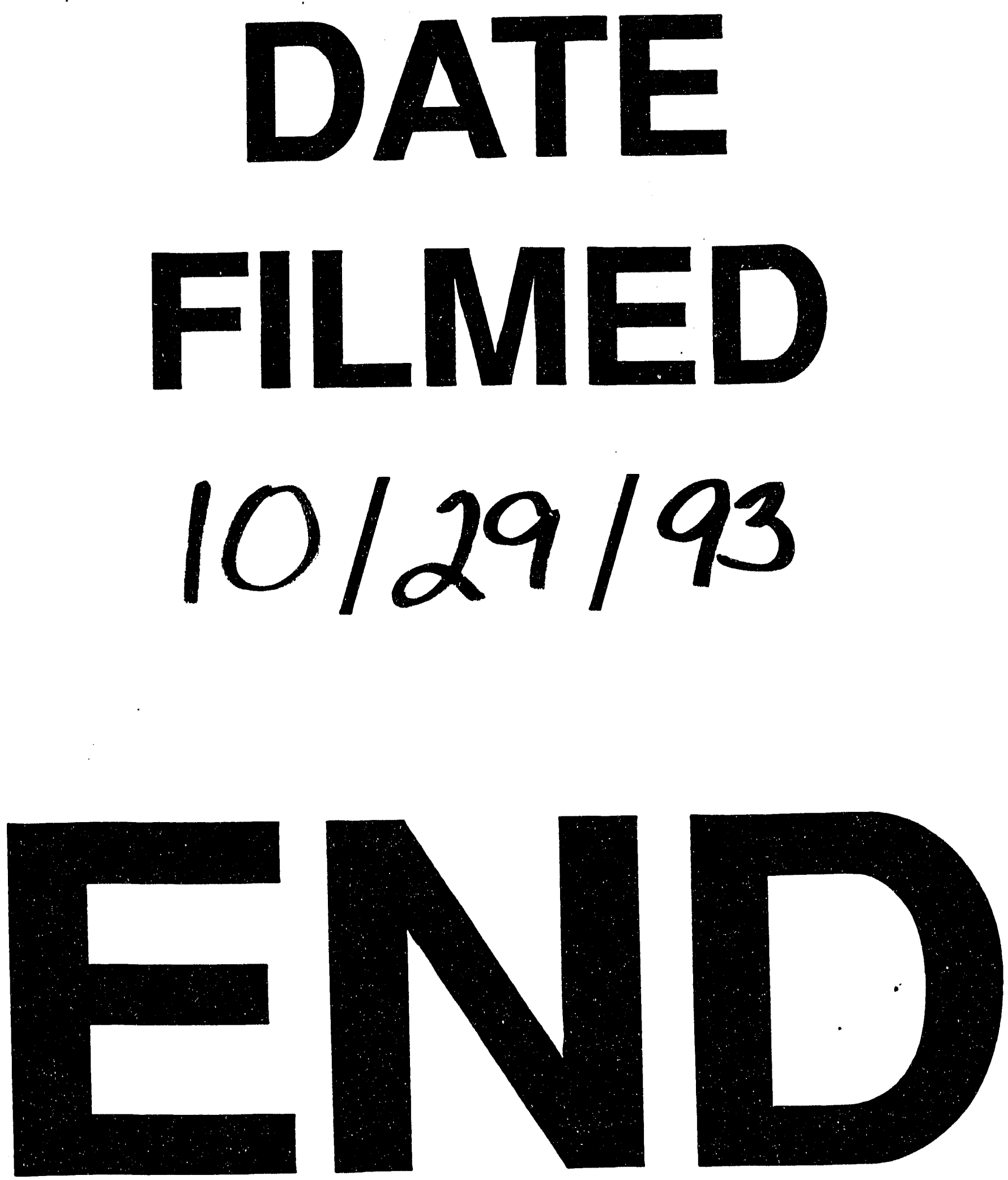
- . . . . - ב 